\title{
Cannabis cnidoscolus - uma proposta de reserva para o comércio legalizado da maconha
}

\section{Cannabis cnidoscolus - a reserve proposal for the legalized marijuana trade}

\section{Esteban Lopez Moreno}

Programa de Pós-Graduação em História das Ciências e das Técnicas e Epistemologia (HCTE) e Programa de Pós Graduação em Ensino de Química (PEQUI), Universidade Federal do Rio de Janeiro (UFRJ)

Fundação Centro de Ciências e Educação Superior a Distância do Estado do Rio de Janeiro (Cecierj) estebanlmoreno@gmail.com orcid.org/0000-0001-8751-2049

\section{Mércio Pereira Gomes}

Programa de Pós-Graduação em História das Ciências e das Técnicas e Epistemologia (HCTE), Universidade Federal do Rio de Janeiro (UFRJ)

merciogomes@gmail.com

orcid.org/0000-0001-7731-273X

Resumo. O mundo caminha aparentemente a passos largos, para a regularização do consumo recreativo da maconha. Já vimos isso acontecendo na Europa, nos Estados Unidos e no Uruguai. O consumo medicinal já é legal em muitos outros países. Subjaz nesta passagem uma oportunidade histórica singular de proporcionar às comunidades de baixa renda, as nossas favelas -- que, de tão carentes em serviços urbanos, abrem-se para a formação de grupos de jovens que se vinculam diretamente a este comércio, o qual, por ilegal, cria ambientes de violência e criminalidade -- uma vantagem comercial que lhes traria benefícios diretos e, por extensão, consequências sociais e econômicas positivas para toda a sociedade brasileira. Neste artigo apresentamos para debate acadêmico uma proposta de reserva de mercado e analisamos alguns dos desafios e consequências que traria para a sociedade.

Palavras-chave: Legalização da maconha. Inclusão social. Favelas. Comunidades de baixa renda. Justiça social. 


\begin{abstract}
The world is apparently striding towards regularizing recreational marijuana consumption. We have seen this happening in Europe, the United States and Uruguay. Medicinal consumption is already legal in many other countries. This passage underlies a unique historic opportunity to provide low-income communities with our favelas - which, because they are so lacking in urban services, open themselves to the formation of groups of young people who are directly linked to this trade, which, by illegal, it creates environments of violence and criminality - a commercial advantage that would bring them direct benefits and, by extension, positive social and economic consequences for the whole of Brazilian society. In this article, we present a market reserve proposal for academic debate and analyze some of the challenges and consequences it would bring to society.
\end{abstract}

Keywords: Marijuana llegalizing. Social inclusion. Shanty towns. Low-income communities. Social justice.

Recebido: 01/10/2017 Aceito: 27/10/10 Publicado: 05/11/2017

\title{
1. Informações gerais
}

Se há um tema que causa debates acalorados em nossa sociedade é a demanda pela legalização da maconha. Apesar da proibição, a maconha ainda é a droga ilícita mais usada no mundo e no Brasil (GALDUROZ J.C., 1997). Diversos estudos corroboram que esta planta é prejudicial à saúde, especialmente na adolescência (SOARES-WEISERS et al., 2003), no agravamento de quadros de esquizofrenia (VAN OS, 2012) ou no prejuízo do processo de aprendizagem (POPE et al., 2001), entre outras, o que no entanto tem sido questionado pela própria comunidade científica (RIBEIROS et al 2005).

Por outro lado, há fortes indícios demonstrando efeitos benfazejos da maconha na prevenção e tratamento de Alzheimer (CURRAIS et. al., 2006), o que permitiu sua legalização como uso medicinal em diversos países, inclusive no Brasil (Resolução da Diretoria Colegiada da Anvisa - RDC 17/2015 ). O uso desta planta corrobora também com resultados positivos no tratamento de dores (analgésico), glaucoma, depressão, ansiedade (KALANT, H., 2001; BONFA, 2008) e até na cura de dependência de outras drogas, como crack e cocaína (LABIGALINI, 1999). Ademais, com o fim da proibição da produção e comércio da maconha haverá uma enorme redução dos custos econômicos e sociais para a manutenção do aparelhamento policial e da justiça, beneficiando outros setores, como a saúde e educação (MARIZ, 2016; MORAES, 2015), ainda que pesem argumentos contrários (Azevedo, R., 2014) ou problematizadores (LARANJEIRA, 2010; BESSA, 2010).

Devemos também considerar que não há qualquer caso na literatura científica que comprove que há algum dano ao organismo no consumo ocasional ou moderado da 
maconha (SOARES-WEISER et al., 2003) e não faltaram esforços para que se o encontrassem. Para muitos autores, o motivo principal ou o único para a proibição da maconha é ideológico, conforme sintetizado por Burgierman \& Nunes (2016):

A guerra contra essa planta foi motivada muito mais por fatores raciais, econômicos, políticos e morais do que por argumentos científicos. E algumas dessas razões são inconfessáveis. Tem a ver com o preconceito contra árabes, chineses, mexicanos e negros, usuários frequentes de maconha no começo do século XX. Deve muito aos interesses de indústrias poderosas dos anos 20, que vendiam tecidos sintéticos e papel e queriam se livrar de um concorrente, o cânhamo. Tem raízes também na bem-sucedida estratégia de dominação dos Estados Unidos sobre o planeta. E, é claro, guarda relação com o moralismo judaico-cristão (e principalmente protestante-puritano), que não aceita a ideia do prazer sem merecimento.

Assim é que, resguardadas as surpresas históricas que porventura emerjam desse nosso confuso tempo, o mundo hoje caminha para a regularização da maconha. No Brasil, a legalização do consumo recreativo não tem previsão para ocorrer, mas seguindo a tendência mundial, como a regulamentação gradual em países como Holanda, EUA, Portugal, Uruguai e em breve o Canadá, é possível que ocorra nos próximos 10 ou 20 anos. Soma-se a este movimento o interesse de grandes corporações financeiras, que veem como uma possibilidade de ampliar o leque de seus produtos e locupletar enormes somas de capital. Não por menos, muitos ou, provavelmente, a maioria dos economistas (MORAES, 2015) tem posições favoráveis à legalização e regulação de um mercado que anualmente movimentaria somente no Brasil $\mathrm{R}$ \$ 5,7 bilhões ao ano, com perspectiva de gerar uma arrecadação de R $\$ 5$ bilhões somente em impostos (MARIZ, 2016). Entretanto, até o momento não se apresentou uma maneira clara e precisa de como seria feita a mudança.

Dada a possibilidade de legalização recreativa da maconha no Brasil, eis aqui algumas considerações sobre a implantação de um modelo de comercialização criativo e beneficente para as comunidades carentes brasileiras,

- Será garantida pelo prazo mínimo de 10 anos a exclusividade do comércio da maconha nas favelas e demais comunidades carentes, tradicionalmente já envolvidas em seu comércio;

- os representantes comerciais serão selecionados a partir de livre concorrência entre os moradores ou representantes da comunidade, após ampla discussão pública;

- em contrapartida, os novos empreendedores deverão oficializar o seu comércio seguindo todas as prerrogativas da lei, esmerando-se pela qualidade e a idoneidade de seus produtos e serviços; 
- ao governo caberá estabelecer as leis e os mecanismos necessários para fiscalizar e garantir a qualidade, a concorrência pacífica entre os empreendedores, a limitação da venda dos produtos para jovens ou pessoas em situação de risco, campanhas educativas e a cobrança de impostos;

- os impostos arrecadados devem ser dirigidos preferencialmente para a saúde e a melhoria do capital humano dessas comunidades;

- após o período de concessão e durante intervalos intermediários, serão avaliados por uma comissão própria os benefícios e prejuízos desta proposta.

\section{Quais são os desafios dessa política?}

Os desafios são imensos, elencamos a seguir alguns dos principais, começando pela ponderação apresentada pelo jurista M. A. Bessa ao analisar o que poderia vir a acontecer com a legalização da maconha: "A simples legalização das drogas não alterará em nada as condições que fazem com que esses jovens tenham no tráfico, muitas vezes, a única alternativa de trabalho e de renda. (...)" (BESSA, 2010)

Nos simples termos de uma legalização, com efeito, nada muito diferente acontecerá de positivo para os grupos de jovens que vendem o produto de modo ilegal. No entanto, a liberação do uso recreativo da maconha em conjunto com a regularização de seu comércio nas favelas deverá atrair mais consumidores para este mercado, trazendo maior oportunidade de emprego e benefícios àquele jovem que opte por sair do tráfico. A forte injeção de recursos nas favelas deve proporcionar diversos outros benefícios para o jovem.

Outras formas de criminalidade continuarão presentes nos morros, incluindo o comércio e outras drogas que permanecerão como ilícitas, como o crack, ácido lisérgico (LSD) etc.

Sim, continuarão. Mesmo drogas legalizadas como o cigarro e o álcool possuem uma indústria ilegal paralela que escapa da tributação e do controle sanitário. A legalização da maconha do Uruguai, tampouco, até o momento, diminuiu o tráfico naquele país. O que se espera é que a violência como um todo diminua na medida em que ocorra um maior sentimento de pertencimento da parcela menos favorecida da população, junto com uma política de melhoria de acesso ao saneamento, transporte coletivo, bons hospitais e escolas. O fortalecimento do comércio local seria efetivamente um dos fatores mais importantes para a diminuição da criminalidade (JACOBS, 2011).

Vejamos as ponderações de Laranjeirta (2010):

“A abolição das leis teria um efeito maior nas pessoas que comumente não consomem drogas, potencialmente levando um maior número a experimentar e a se tornar usuário regular ou esporádico". (Laranjeira, 2010) 
Considerando-se o cenário aqui proposto, o aumento do consumo da maconha com a legalização é provável e, para alguns propósitos, indesejável. Não obstante, os principais danos decorrentes do consumo da maconha são causados pela forma como a sociedade lida com esta planta, não pelo uso em si. Ademais, com o fortalecimento da presença do Estado nas comunidades que antes eram dominadas pelo tráfico, espera-se um efetivo aumento do conhecimento consciente da população usuária ou potencialmente usuário, o que pode ser reforçada em campanhas, como já ocorrem em relação ao uso do tabaco e do álcool. O Estado estaria também mais apto a oferecer um tratamento público digno aos usuários dependentes de todos os tipos de drogas.

\section{E quem produziria e beneficiaria a maconha?}

Não temos clareza neste ponto. Nosso ensejo até o momento é que estas etapas de produção sejam livres, seja em ambiente urbano ou rural, apenas regulamentadas pelo Estado e sem qualquer reserva para comunidades, como já ocorre com o tabaco. De outra sorte, caso a produção seja monopolizada pelo Estado ou por empresas privadas, incorrerá fatalmente em uma forte produção clandestina. Por outro lado, a livre produção, ainda que regulamentada, provocará o aumento da concorrência e a diminuição do preço e dos lucros, enfraquecendo o interesse dos empresários pelo comércio da maconha. A venda das drogas ilícitas se tornaria, por isso, mais lucrativa. Há ainda uma série de variáveis imprevisíveis nesta questão.

Trazendo de novo as ponderações de Bessa:

"Será que se pode imaginar que a simples legalização afastará as facções do crime organizado que desempenham essas funções de atividade ilícita e fará com que eles apareçam à luz, legalizem-se e se tornem respeitáveis cidadãos, pagantes de impostos, tementes a Deus e às leis? Transformem-se do dia para a noite em empresários sérios, participativos de campanhas beneficentes, patrocinadores de ações sociais solidárias voltadas especialmente às crianças e jovens carentes? Terão o mesmo comportamento nobre e desinteressado que seus colegas das indústrias do tabaco e das bebidas alcoólicas tiveram ao longo da história e mantêm em nossos dias? “ (BESSA, 2010)

É muito difícil afirmar com total convicção que tal efeito ocorra, entretanto foi assim que aconteceu em alguns países. A Austrália é um bom exemplo. Durante sua colonização no século XVIII uma parcela significativa de sua população era composta de réus condenados e deportados da Inglaterra. A partir do momento que a sua economia tornouse mais inclusiva, permitindo a participação ativa desses criminosos, este país se tornou uma dos mais prósperos do planeta. O mesmo ocorreu por diferentes mecanismos com os EUA, Canadá e Nova Zelândia e tem sido hoje considerada como a melhor estratégia para melhorar a situação de países pobres, ao invés da simples transferência de recursos por meio de ações sociais. O que certamente nunca ocorreu foi o "comportamento nobre e desinteressado" das indústrias de álcool e tabaco, trata-se naturalmente de uma ironia. 
É preciso considerar que os resultados das ações aqui propostas podem ser imprevisíveis. Para que se potencialize os efeitos desejados, é necessário que o comércio legalizado seja inicialmente implantado de modo experimental em algumas poucas comunidades, de porte pequeno, como o Morro Dona Marta, na Zona Sul do Rio de Janeiro. Ao menos por algum pouco tempo, esse experimento servirá como um laboratório de estudo cujos resultados podem vir a ser multiplicados, com os devidos cuidados, em outras comunidades.

\section{Palavras finais}

A Cannabis sativa, nome científico da maconha, é um arbusto da família das Moraceae que cresce em diversas partes do planeta, nas regiões tropicais e temperadas. É provável que suas sementes tenham sido trazida para o Brasil por escravos africanos, a partir de cuja prática lúdica e cerimonial se fez corriqueiro o seu uso entre a população pobre, livre ou cativa, pelo interior do Brasil. No Rio de Janeiro, boa parte de seu comércio dá-se nas "favelas". Este nome, por sua vez, é oriundo de um arbusto de flores brancas, com espinhos e sementes em forma de "favas", cujo nome científico é Cnidoscolus Quercifolius, e é endêmica em regiões áridas do Brasil. Os soldados que retornaram ao Rio de Janeiro após participarem da guerra que destruiu a comunidade messiânica de Canudos, talvez o último reduto da resistência indígena-mestiça aos poderes estabelecidos, sem terem um merecido local para construir suas casas e morar, foram ocupando principalmente os morros da cidade, construindo barracos e casebres, constituindo comunidades, e acabaram por designar essas novas formas de moradia e vivência pelo nome da planta que tanto os havia impressionado em sua terrível passagem pelos sertões baianos. Será que houvera aí alguma identidade escondida?

No imaginário de nós, autores, estas duas plantas enquanto isoladas têm representado preconceito, violência e injustiça; no entanto se tratadas juntas e misturadas, i.e., como Cannabis Cnidoscolus, simbolizam um encontro que nos leva a uma perspectiva de apaziguamento e a uma tão desejada justiça social. Trata-se, pois, de uma proposta criativa e original, bem ao estilo de nossa brasilidade.

\section{Financiamento}

O presente trabalho foi realizado com apoio da Coordenação de Aperfeiçoamento de Pessoal de Nível Superior - Brasil (CAPES) - Código de Financiamento 001.

\section{Referências}

AZEVEDO, Reinaldo, Um manifesto contra a legalização das drogas no Brasil; se concordar, assine, revista Veja, publicado em 24 jun 2014. http://veja.abril.com.br/blog/reinaldo/um-manifesto-contra-a-legalizacao-das-drogas-nobrasil-se-concordar-assine/ Acesso em 4 de outubro de 2017. 
BESSA, M.A.; Contribuição à discussão sobre a legalização de drogas. Ciência e Saúde Coletiva, vol. 15 (3): pp. 632-636, 2010

BURGLERMA, D. NUNES, A., A verdade sobre a maconha, Revista Superinteressante, 2016. Disponível em: https://super.abril.com.br/ciencia/a-verdadesobre-a-maconha/, acesso em 5 de setembro de 2017.

BONFA, Laura; VINAGRE, Ronaldo Contreiras de Oliveira; FIGUEIREDO, Núbia Verçosa de. Uso de canabinóides na dor crônica e em cuidados paliativos. Rev. Bras. Anestesiol., Campinas , v. 58, n. 3, p. 267-279, jun. 2008 .

KALANT, H. Medicinal use of cannabis: history and current status. Pain Res Manag, 2001; 6:80-91.

CURRAIS, Antonio \& QUEHENBERGER, Oswald \& ARMANDO, Aaron \& DAUGHERTY, Daniel \& MAHER, Pam \& SCHUBERT, David. Amyloid proteotoxicity initiates an inflammatory response blocked by cannabinoids. Aging and Mechanisms of Disease. 2. 16012, 2016. DOI: 10.1038/npjamd.2016.12.

LABIGALINI, Eliseu, RODRIGUES, Lucio Ribeiro, DA SILVEIRA, Dartiu Xavier, Therapeutic Use of Cannabis by Crack Addicts in Brazil, Journal of Psychoactive Drugs Vol. 31 , Iss. 4, 1999

GALDURÓZ J.C., NOTO, A.R., CARLINI, E.A. IV Levantamento sobre o uso de drogas entre estudantes de 10 e 20 graus em 10 capitais brasileiras. São Paulo: Centro Brasileiro de Informações sobre Drogas Psicotrópicas (CEBRID); 1997.

JACOBS, Jane. Morte e Vida de Grandes Cidades, São Paulo, Wmf Martins Fontes, 3a ed., 2011.

LARANJEIRA, Ronaldo. Legalização de drogas e a saúde pública. Ciênc. saúde coletiva, Rio de Janeiro, v. 15, n. 3, p. 621-631, May 2010 .

MARIZ, Renata, Comércio formal de maconha movimentaria R\$ 5,7 bilhões no Brasil. Estudo de consultores da Câmara avalia impacto econômico da legalização. Revista Veja. 09/06/2016, disponível em https://oglobo.globo.com/sociedade/comercio-formalde-maconha-movimentaria-57-bilhoes-no-brasil-19468621\#ixzz4uZJp3rT6 
MORAES, Pedro Rocha de. A proibição da maconha no Brasil e suas implicações econômicas: uma análise dos custos incorridos e evitados. 2015. 77 f., il. Monografia (Bacharelado em Ciências Econômicas)—Universidade de Brasília, Brasília, 2015. Disponível em: http://bdm.unb.br/bitstream/10483/11445/1/2015_PedroRochadeMoraes.pdf

POPE H.G. Jr, GRUBER AJ, HUDSON JI, HUESTIS MA, YURGELUN-TOSS D. Neuropsychological performance in long-term cannabis users. Arch Gen Psychiatry 2001;58:909-15.

RIBEIRO, Marcelo et al . Abuso e dependência da maconha. Rev. Assoc. Med. Bras., São Paulo, v. 51, n. 5, p. 247-249, Oct. 2005.

SOARES-WEISER, Karla; WEISER, Mark; DAVIDSON, Michael. Uso de maconha na adolescência e risco de esquizofrenia. Rev. Bras. Psiquiatr, São Paulo, v. 25, n. 3, p. 131-132, Sept. 2003.

Van Os J1, BAK M, HANSSEN M, BIJL RV, de GRAAF R, VERDOUX H.. Cannabis use and Psychosis: a longitudinal population based study. Am J Epidemiol 2002; 156: 319-27. Disponível em: https://www.ncbi.nlm.nih.gov/pubmed/12181101 